London, being a good and desirable thing of which we cannot have enough, should split itself up into two parts - a southern and a northern one- $a$ province of Canterbury and a province of York, and that the various provincial colleges in the north should form members of the great University representing the northern province.

Our reply to this proposal is that believing the University of London to represent an incomplete system we are unwilling to contemplate its universal extension whether this be brought about by the process of absorption or by that of fission.

It is alleged by some who favour this system of grouping colleges together into one University, that a healthy principle of competition is introduced into the teaching departments of the various colleges, and they quote in favour of their views the success of the University of Cambridge in producing eminent mathematicians by this system. We shall here confine ourselves to showing that this supposed analogy is delusive. What the various colleges do, and do extremely well, is to impart a moral and social training to their pupils; but it is well known that in Cambridge the real rivalry as regards mathematical honours is not between the various colleges, but between the various private tutors. The chances are in favour of a certain tutor turning out the next senior wrangler, and accordingly the inmates of the various colleges rush off to this tutor in the hope of gaining the great prize. What this system demonstrates is rather the necessity of a thorough system of tutors in addition to that of professors, in order to secure the high proficiency of a few in any department.

Thus by a species of exhaustion, and by discussing the various alternatives suggested, we come to see that we must look to the various individual provincial colleges to become the future Universities of our country; and the only question that remains is whether Owens College be yet ripe for the change. Let us present the claims of this College to our readers in the language of the pamphlet already alluded to :-

"It remains to inquire whether Owens College may be fairly considered equal to the assumption of such a position, and whether the present period is a suitable one in its history for the College to advance such a claim. The history of the College may in any case be said to have prepared it for a University future. Owens College was founded to provide instruction 'in such branches of leaming and. science as were then and might be thereafter usually taught in the English Universities,' and it has uniformly sought to pursue a course and maintain a character consistent with this intention on the part of its founder. The support given to it in the district has indisputably been largely given as to an institution desiring to hold an academical level. ... As to curricula and branches of teaching, the Senate, while unwilling to enter into details, have no hesitation in asserting their opinion that Owens College may, taken as a whole, fairly challenge comparison with any academical institutions of this and with some of other countries. We have here a ready-formed and-in essentials-complete University organisation as regards the Faculties of Arts, Science, and Medicine, together with a newly-formed School of Law. . . . The Faculty of Divinity is indeed absent; but apart from the reasons which, in Owens College as well as elsewhere, have caused its absence, it may be worth observing that the conception of a University by no means involves the necessity that it should possess chairs and grant degrees in all the faculties. This posi- tion it would be easy to prove from the history of several Universities of European fame."

This is an era of great educational activity ; attempts are being made to reform our great English institutions, and a Commission is at present engaged in discussing the future of the Scotch Universities.

We are convinced that an enlightened government will best complete its efforts in this direction by giving a University Charter to Owens College, not, however, as a last and crowning concession, but rather as the first of a series of concessions, all of which, let us hope, will, when the time is ripe for them, be frankly and graciously made. Let there be no disguising the fact that Owens College is but the eldest of a large and rapidly increasing family, others of whom may, we hope, in the course of time, make their appearance before the state. It may, however, be twenty or thirty years hence before any of the recently established institutions is sufficiently ripe to receive the crowning honour of a University Charter. At present no other college can hope to present similar claims representing something like 500 day students, 800 evening students, and a very large arnount of voluntary endowment. This is in truth the work of a generation.

We do not think it probable that any opposition to this movement will arise on the part of the two great English Universities. Their office is rather to lend their distinguished graduates as teachers in these new institutions, and by dint of their own practice and their great influence to see that moral, social, and even physical training are encouraged, as well as training in its merely intellectual aspect. And while they themselves may in the future be probably induced to give a greater prominence to the professorial element than they have yet done, they may in their turn induce the other Universities to encourage the tutorial element to a greater extent. In fine, these two old Universities will, whatever happens, always retain a powerful voice in the educational councils of the nation.

Nor must it be supposed that we advocate the doing away with the University of London, for whatever be the plan adopted there will always be colleges which not having attained to the rank of Universities, must look to that institution as their degree-giving body.

But the function of such an institution is to redress a hardship in the case of pupils rather than to cause and perpetuate a hardship on the part of teachers. The University of London will be heartily welcomed as a channel for imparting a degree that could not othewise be procured, but it ought not to be tolerated as a Procrustean bed for the education of the country. In fine, it was founded as the most available means of redressing a grievance, and for this very reason it is necessarily incomplete.

So long as we continue to progress-solong as colleges multiply and are not yet able to grant degrees,-so long must we retain an institution similar to the present University of London.

\section{AGRICULTURAL WEATHER-WARNINGS IN} FRANCE

A $N$ important step has been taken by Le Verrier in the application of meteorology to practical matters by the inauguration of a system of weather-warnings specially designed for the benefit of agriculturists. The 
chicf features of this system of warnings are briefly sketched in a recent number of the Bulletin Hebdomadaire of the Scientific Association of France.

Weather-warnings intended to be useful to the agricultural interest are essentially different from those issued for the benefit of navigation. What sailors require almost exclusively to know is, the force and direction of the wind in approaching storms. On the other hand, what agriculturists require to know is a knowledge of coming rains and of thunderstorms, especially the destructive hail which often accompanies them; whilst the wind, save in rare exceptional cases, little affects them. The ability to foretell rain, the causes of which depend on conditions absolutely different in different parts of France, is unquestionably one of the most intricate problems of science, and therefore demands the closest study, wide knowledge, and sound judgment in working out its successful solution.

When, eighteen years ago, the Paris Observatory, established a system of warnings for the French Marine, the conditions for carrying them out successfully were not known. Now, however, owing to the experience acquired, the observatory is able to issue warnings of so useful a nature, that no serious storm makes its appearance in the Channel, or on the shores of the Bay of Biscay, or of the Mediterranean, which has not previously been announced to the seaports menaced by it. To-day the difficult question of agricultural warnings presents conditions of uncertainty similar to those which warnings for navigation presented in 1858 . The present difficulty, therefore, is no reason for doing nothing, but only a reason for greater care and more strenuous exertion. Mistakes will necessarily be made at the first, probably numerous during the first year, seeing that there is still no precise basis on which to rest; they will, however, diminish as experience is acquired, and doubtless the time will by and by come when warnings for agriculture will be attended with a like success as now characterises warnings for navigation.

Agricultural warnings cannot, then, as in the case of warnings for navigation, be issued to the provinces by the Paris Observatory in an absolute form. It is, at this early stage, indispensable that the warnings sent to the chief places of the departments be of a general character to be supplemented and modified by local meteorological experts, who, in doing so, must be guided by their knowledge of the local peculiarities of their particular districts. This mode of procedure will furthermore lead to a thorough examination and a more exact knowledge of the meteorology of France.

The points to be more specially investigated by the departmental Meteorological Commissions at the outset, are these:-I. To follow and investigate the march of the rainfall, not only as regards quantity, but as regards the mode in which it is successively propagated from canton to canton, and from department to department, particularly when, after a season of drought, rainy weather begins to set in. 2. As regards thunderstorms (orages), the chief point to be attended to is that information of their first appearance be sent to the chief place of the department in which they occur, which, in its turn, will telegraph the fact to the Paris Observatory, so that the officials there may, in view of the whole circumstances, send timely warnings to those depaxtments which appear to be threatened by the storm. 3. Since little is yet really known of hailstorms, which are often so disastrous to agriculture, it will be necessary to give instant attention to collect such data as may likely lead to some knowledge of the influence of woods, hills, and river-courses on the origin and progress of the hailstorm. 4. In connection with the late frosts of spring, which are productive of such enormous loss to agriculture, the often-alleged effect of smoke in counteracting their blighting influence will be brought to the test of experiment on a large scale, say over the whole extent of a valley. 5. Lastly, warnings relative to inundations cannot but excite the liveliest interest, in consideration of the national disasters of recent years, which might have been to a large extent lessened, if not in many cases averted altogether, if a proper system of such warnings had been in operation. To the civil and mining engineers to whom these warnings have been entrusted, the service of the agricultural warnings will necessarily lend much valuable assistance.

Agricultural weather-warnings began to be issued by the Paris Olservatory, on May I, to the three departments of Vienne, Haute-Vienne, and Puy-de-Dôme, the telegraphic authorities giving the free use of the wires in the transmission of the messages. In order to give a fair trial to this initial experiment the system will be continued daily till October 1, i 876 , after which the whole matter will be submitted to a careful reconsideration.

The following example will show the method employed in carrying out the system:-On May 7 the Observatory, to show the general course of the isobarics over Europe, telegraphed that the barometer at $32^{\circ}$ and sea-level was 29.607 inches at Palermo, 29.725 at Naples, Florence, Perpignan, and Madrid, 29.922 at Moscow, Berne, Limoges, and Bordeaux, 30.19 at Petersburg, Paris, and Lorient, $30^{\circ} 316$ at Helsingfors, Helder, and Greencastle, and 30.512 at Hernösand, and Skudesnes. Attention was further drawn to the fact that pressure was not only high in Sweden, but that it had risen 0.393 inch, and not only low in Sicily, but had fallen 0.196 inch; and that since under this two-fold infuence a polar current was flowing over Europe towards the Mediterranean, northern and easterly winds would continue to prevail, bringing with them generally clear skies and, owing to the strong sunheat, an increase of temperature during the day. This prediction, it is needless to add, was verified by the event.

We most heartily wish every success to this bold and novel system of weather-warnings, designed for the benefit of great national interests. It may be added that it is on a sound practical knowledge of the thunderstrorm, considering the term in its widest significance, that the success of these warnings will depend; and it is, therefore, singularly fortunate that in no country hsa so much well-directed labour and expense been bestowed on the investigation of thunderstorms as in France.

$$
\text { RADCLIFFE'S "VITAL MOTION" }
$$

Vital Motion as a Mode of Physical Motion. By Charles Bland Radcliffe, Doctor of Medicine, \&c. (London: Macmillan and Co, 1876 .)

$A \mathrm{~S}$ there is a growing conviction of the importance of A studying physiology from the side of physics, so we may be led to value more the efforts made in this line 